\title{
O EMPODERAMENTO DA MULHER QUEIMADA POR AUTOIMOLAÇÃO E SUA SUSTENTAÇÃO NA RELIGIÃO E ESPIRITUALIDADE
}

\section{Empowerment of women burned by self-immolation and their support in religion and spirituality}

\author{
El empoderamiento de la mujer quemada por auto inmolación y su sustentación \\ en la religión y la espiritualidad
}

\author{
Rafaele Teixeira Borges \\ Universidade de Fortaleza - UNIFOR - Fortaleza (CE) - Brasil \\ Faculdade Ateneu - FATE - Fortaleza (CE) - Brasil \\ Cristiane Silva Lira \\ Faculdade de Ensino e Cultura do Ceará - FAECE - Fortaleza (CE) - Brasil
}

Raimunda Magalhães da Silva

Universidade de Fortaleza - UNIFOR - Fortaleza (CE) - Brasil

Jonas Loiola Gonçalves

Instituto de Educação Ateneu - Fortaleza (CE) - Brasil

Paulo Félix de Almeida Pena

Universidade de Fortaleza - UNIFOR - Fortaleza (CE) - Brasil

\section{RESUMO}

Objetivo: Identificar a relação da espiritualidade e da religiosidade no empoderamento da mulher queimada por autoimolação. Métodos: Estudo qualitativo, realizado com cinco mulheres com sequelas de queimaduras por autoextermínio. A coleta de dados ocorreu por meio de um roteiro de entrevista semiestruturada. A análise baseou-se no método de "narrativa da doença" com suporte nos discursos das mulheres. Resultados: As mulheres com cicatriz hipertrófica apresentaram reações diversas e, com os discursos destas, emergiram as categorias: a) "Deus tirou tudo aquilo da minha cabeça", que relatava a religião como ponto alto da salvação; b) "Estigma em relação ao corpo queimado", na qual reconhece a estigmatização e a resposta da vítima diante da rejeição da sociedade. c) "O corpo e o autopreconceito", representativas da não aceitação da nova imagem corporal, auto-rejeição, autopreconceito e a espiritualidade no processo de empoderamento da mulher queimada. Conclusão: A mulher vítima de queimadura demonstra múltiplas nuances em relação a autoimagem e autoestima. A fé na religião e na espiritualidade ajuda na superação dos conflitos pessoais e sociais.

Descritores: Queimaduras; Poder (Psicologia); Estigma Social; Espiritualidade.

\section{ABSTRACT}

Objective: To identify the relationship of spirituality and religiosity with the empowerment of women burned by self-immolation. Methods: A qualitative study was carried out with five women with burn scars caused by self-immolation. Data were collected using semi-structured interviews. Data analysis was performed on the basis of the illness narrative method and was supported by women's accounts. Results: Women with hypertrophic scars reacted in different ways and their accounts gave rise to the following categories: a) "God took all that out of my head", which showed religion as highlight of salvation; b) "Stigma related to the burned body", which acknowledges women's stigmatization and responses to the rejection by the society; c) "The body and self-prejudice", which describes the representations of non-acceptance of the new body image, self-rejection, self-prejudice and spirituality in the process of empowerment of burned women. Conclusion: Burned women present with multiple nuances regarding self-image and self-esteem. Faith in religion and spirituality helps overcoming personal and social conflicts.

Descriptors: Burns; Power (Psychology); Social Stigma; Spirituality. 


\section{RESUMEN}

Objetivo: Identificar la relación de la espiritualidad y la religiosidad para el empoderamiento de la mujer quemada por auto inmolación. Métodos: Estudio cualitativo realizado con cinco mujeres con secuelas de quemaduras por auto exterminio. La recogida de datos se dio a través de una guía de entrevista semi-estructurada. El análisis se basó en el método de "narrativa de la enfermedad" apoyado por los discursos de las mujeres. Resultados: Las mujeres con cicatriz hipertrófica presentaron reacciones diversas y se emergieron las siguientes categorías de sus discursos: a) "Dios ha sacado todo aquello de mi cabeza", en el que la religión es el punto alto para la salvación; b) "Estigma del cuerpo quemado" en la cual se reconoce la estigmatización y la respuesta de la víctima delante del rechazo de la sociedad; c) "El cuerpo y el auto prejuicio", representativos de la no aceptación de la nueva imagen corporal, el auto rechazo, el auto prejuicio y la espiritualidad en el proceso de empoderamiento de la mujer quemada. Conclusión: La mujer víctima de quemadura demuestra múltiples matices respecto el auto imagen y la autoestima. La fe en la religión y la espiritualidad ayudan para la superación de los conflictos personales y sociales.

Descriptores: Quemaduras; Poder (Psicología); Estigma Social; Espiritualidad.

\section{INTRODUÇÃO}

No Brasil acontece um milhão de queimaduras por ano, sendo que 200 mil pessoas são atendidas em serviço de emergência e 40 mil são hospitalizadas. Estas injúrias são as principais causas de morte por fatores externos, perdendo apenas para acidentes automobilísticos e homicídios, gerando grandes repercussões psicológicas ${ }^{(1,2)}$.

As alterações físicas e psicológicas levam a ideações, tentativas e atos suicidas, atraindo a atenção e os estudos das diversas áreas científicas. Define-se suicídio como um ato consciente de autodestruição, ato intencional de uma pessoa para extinguir sua própria vida( ${ }^{(3)}$.

Tentativa de autoextermínio é todo caso de morte resultante direta ou indiretamente de um ato positivo ou negativo da vítima, de forma intencional, na qual se deflagra a morte, como a perda da vontade de viver, o desejo ou a intenção de autodestruição(4,5).

Religião e espiritualidade são condicionantes na maneira da pessoa encarar a vida e a morte. Desde tempos remotos que as crenças, práticas e experiências espirituais têm sido compostas influentes nas sociedades. Profissionais de saúde, pesquisadores e a população em geral reconhecem a importância da dimensão religiosa/ espiritual para a saúde ${ }^{(3)}$.

Religiosidade envolve um sistema de culto e doutrina, compartilhado por um grupo, com características comportamentais, sociais e doutrinárias específicas. Espiritualidade relaciona-se com o transcendente, com aspectos definitivos sobre o significado e propósito da vida ${ }^{(4)}$. A experiência religiosa deixou de ser considerada fonte de patologia e passa a ser reconhecida como provedora do reequilíbrio(5).

Todo percurso pós-queimadura e ato de autoextermínio perpassa atos de estigmatização. Socialmente, é atribuída a esta pessoa uma imagem perante o acontecido e esquecem o ser humano vítima do seu ato suicida. $O$ sofrimento surge perante os padrões que são submetidos e às exigências impostas pela sociedade ${ }^{(6)}$.

As relações entre a nova imagem corporal, autoextermínio, religião e espiritualidade são processos tênues para o auxilio e direcionamento da promoção da saúde da pessoa vítima de queimaduras por autoextermínio.

Neste sentido, procurou-se identificar a relação da espiritualidade e da religiosidade no empoderamento da mulher queimada por autoimolação.

\section{MÉTODOS}

Este estudo tem metodologia qualitativa, baseando-se na concepção de entender o significado individual ou coletivo para a vida das pessoas e não o fenômeno em si ${ }^{(7)}$. Optou-se pelo método da "narrativa da doença"(8), que considera saúde e todos os processos envolvidos com resultado de fenômenos culturalmente constituídos e interpretados. A maneira como se percebe e a busca por superação da doença é moldada culturalmente.

Participaram deste estudo cinco mulheres com sequelas de queimaduras do tipo cicatrizes hipertróficas, com idade acima de 18 anos, com condições físicas e psicológicas para responder à entrevista e mediante assinatura do Termo de Consentimento Livre e Esclarecido. Excluíram-se as mulheres que ainda estavam em tratamento de suas queimaduras. 
A coleta de dados foi realizada no domicílio das mulheres nos meses de agosto e setembro de 2013 , em Fortaleza, Ceará. Recorreu-se a entrevista semiestruturada, com quesitos sobre cicatrizes hipertróficas, estigma e espiritualidade/religião, utilizando-se um gravador para registrar os dados.

Diante dos dados transcritos e após repetidas leituras e reflexões, analisaram-se os mesmos segundo a "narrativa da doença", dos quais emergiram as seguintes categorias: a) "Deus tirou tudo aquilo da minha cabeça", que relatava a religião como ponto alto da salvação, encontrando na fé em Deus e na religião a coragem de enfrentar a nova imagem corporal; b) "Estigma em relação ao corpo queimado", em que é reconhecida a estigmatização e expressa o modo como a vítima cria defesas para conviver com a rejeição da sociedade e c) "O Corpo e o autopreconceito", que representa a não aceitação da nova imagem corporal, refletindo autorrejeição, autopreconceito e a espiritualidade no empoderamento.

A investigação recebeu aprovação do Comitê de Ética em Pesquisa da Universidade de Fortaleza sob Parecer $n^{\circ}$. 323.476, sendo respeitados os preceitos éticos da Resolução 466/12 do Conselho Nacional de Saúde que regulamenta pesquisas com seres humanos ${ }^{(9)}$.

\section{RESULTADOS E DISCUSSÃO}

As queimaduras corporais introduzem múltiplas sequelas de caráter funcional, estético e social. As mulheres sobreviventes que responderam à entrevista encontraram na fé um sustentáculo para prosseguir no tratamento e superação de obstáculos. De acordo com os discursos das vítimas de queimaduras destaca-se nas categorias na sequência:

\section{Deus tirou tudo aquilo da minha cabeça}

A fé é uma característica do povo nordestino do Brasil. A exemplo tem-se em Juazeiro do Norte, Ceará, uma estátua em homenagem a Padre Cícero Romão Batista, popularmente conhecido como "Padim Cíço". No norte do Estado, o Município de Canindé recebe romeiros de vários locais, percorrendo grandes distâncias nos chamados paus-de-arara, na intenção de pagar promessas a São Francisco, fazer suas orações e festejar um grande ato religioso ${ }^{(10)}$.

Maria, 41 anos, casada, tentou suicídio, ateando fogo em seu corpo, ela é desempregada, mãe de dois filhos, casada e residente com a família. Relatou uma melhora na relação conjugal após a queimadura, em virtude da religião. Refere que muitas pessoas no hospital comentavam que os maridos das vítimas de queimaduras, geralmente, as abandonavam após o acidente. No caso de Maria, o companheiro permaneceu ao seu lado, dando apoio:

"O relacionamento com o meu marido só melhorou e para a família inteira. Por que antes, assim, eu não tinha uma opção de religião, hoje sou muito religiosa. Isso ajudou a melhorar nosso casamento e a nossa familia."

As práticas voluntárias e o envolvimento em cultos religiosos influenciam diretamente na autoestima. Tais atividades quando não prolongam a vida ou modificam o curso de uma doença física, podem melhorar o propósito de viver sob uma melhor qualidade de vida ${ }^{(11)}$.

O empenho e o respeito a princípios religiosos são possíveis de proporcionar oportunidades para aceitação das dificuldades. A pessoa, ao buscar uma crença religiosa e envolver-se com padrões de religiosidade, adere a um conjunto de valores, símbolos, comportamentos e práticas sociais que promove a aceitação de fatores determinantes na sua felicidade ou não(12).

Apesar de vários episódios de choro na fase inicial da sua recuperação, Maria voltou para casa. Seu medo de ficar sozinha ou de relembrar imagens de fogo transportava sensação de desespero pelo fato de reviver o trauma sofrido. Ela referiu ter superado o medo, porque Deus a ajudou:

"Deus tirou tudo aquilo da minha cabeça, eu entrava em desespero para não pensar ou até mesmo fazer uma outra besteira, mas tudo isso passou. Deus tirou da minha cabeça."

Práticas religiosas exercem influências positivas na saúde mental. O envolvimento religioso traz influências para a melhoria da saúde, incluindo fatores como suporte social, estilo de vida, práticas religiosas e estratégias para enfrentar e vivenciar o estresse ${ }^{(10)}$.

O mecanismo da religião consiste em promover acolhimento, criação de vínculos e apoio social. $\mathrm{O}$ ato de frequentar algum culto religioso e/ou igreja constitui recurso suplementar. A religião tem papel de mediadora no 
propósito dos seus seguidores em adotarem hábitos e estilos de vida saudáveis, como também na produção de valores que eles devem seguir ${ }^{(13)}$.

$\mathrm{O}$ ato religioso constitui recurso eficaz com vistas a evitar comportamento não normativo socialmente, e favorecendo a melhoria do acesso socialmente regular. Tal fato justifica-se pela capacidade da pessoa estabelecer autocontrole e autorregulação sob os aspectos emocional, cognitivo (por meio das crenças) e comportamental para obter sucesso em muitos domínios da vida ${ }^{(14)}$.

No caso de Maria, o acidente foi ocasionado por uma tentativa de suicídio, fato este que fez a conduzir uma nova percepção de valorização da vida, atribuindo essa mudança à ajuda divina. Manifesta vontade em voltar para o hospital, mas na qualidade de transmitir sua fé para pessoas hospitalizadas:

"No meu caso foi uma tentativa de suicídio, aí o que eu fiz, eu não faço mais. Pra mim isso não é nada. Na verdade, só trouxe coisas boas. Se eu tivesse esse pensamento há um ano atrás, eu não tinha feito isso comigo. Agora quero voltar no hospital para passar os ensinamentos do Evangelho."

A religião é apontada como fator de proteção contra pensamentos e comportamentos suicidas. Isto torna necessário observar o significado e a importância que a religião desempenha no cotidiano da pessoa ${ }^{(10)}$.

O apoio religioso, independentemente da religião, é fundamental para a superação dos pensamentos suicidas. As instituições religiosas são tidas como locais de renovação e ressignificação, não somente pelos seus preceitos doutrinários, mas também, por serem ambientes que engajam novos relacionamentos, companheirismo, aprendizado de novas ocupações, levando ao distanciamento do que antes introduzia sofrimento. Pertencer a um grupo religioso significa sentir-se útil, estar vivo, ter oportunidade de falar e ser ouvido, dividir angústias com outras pessoas e exercitar sentimentos de pertencimento e propósitos de vida(15).

Margarida, 36 anos, casada, mãe de dois filhos, possui uma grande fé. Esta fez um pedido a Deus, para retirar da sua cabeça e do coração todos os sentimentos pós-queimaduras. A queimadura foi ocasionada por autoimolação com álcool. Para ela, o que lhe aconteceu trouxe motivação para ajudar as pessoas que passam pela mesma situação:

"Eu fiz um pedido para Deus. Tirar do meu coração toda angústia que eu tinha. Deus tirou. Como eu já estou melhor, eu já penso de pregar o evangelho dentro do hospital. Quase que eu morro, para mostrar para as pessoas que Deus é firme, verdadeiro e fiel."

Atribuir a Deus o motivo de aparecimento de algumas doenças, e até mesmo da morte são para o enfrentamento de como algumas pessoas enfrentam meios emocionais, cognitivos ou comportamentais para tais situações, na qual a religião é estratégia para lidar com eventos estressores ${ }^{(16)}$.

\section{Estigma em relação ao corpo queimado}

$\mathrm{O}$ ato do adoecimento introduz inseguranças, dúvidas, medo do desconhecido e da morte. Ao vivenciar uma doença infecciosa, a vítima lida com estigmas e barreiras criadas na sociedade, o que acarreta rejeição para com aquele que está possivelmente infectado. O estigma ocorre desde os tempos bíblicos e continua fazendo parte do imaginário das pessoas ainda nos dias atuais ${ }^{(16)}$.

Rosa, 56 anos, divorciada, vítima de queimadura por autoimolação, desempregada, vive com o auxílio financeiro das filhas após a queimadura. Relata alguns episódios de olhares curiosos e de rejeição. Esses fatos a levam a crises de choro. Usa malha compressiva nas partes do corpo acometidas pelas queimaduras, como o tórax e membros superiores. Suas cicatrizes são visíveis e isso atrai olhares curiosos:

"Eu sou da igreja, mas um dia fiquei muito chateada. Porque eu uso uma malha e eu sentei perto de uma menina na igreja. Estava com a malha e percebi que ela ficou se afastando assim de mim. Achando que eu tinha uma doença dessas contagiosas. Fiquei muito chateada e chorei muito."

Episódios estigmatizantes repetem-se diariamente, também na vida de Margarida. Para chegar ao local onde realiza tratamento fisioterápico, ela precisa usar um transporte público, dividindo espaço com várias pessoas, deixando-a envergonhada e preocupada pelos olhares:

"Quando eu estou a caminho para fazer tratamento dentro dos ônibus, eu fico logo envergonhada. As pessoas me olham e ao ver as cicatrizes, acham que é alguma doença contagiosa que eu tenho. Eu fico chateada e preocupada." 
A sociedade traz, enraizada na cultura, o medo, o preconceito e o estigma, ao deparar pessoas portadoras de moléstias ${ }^{(16)}$. O corpo sofre um controle poderoso por parte da sociedade em vários aspectos, desde os físicos aos laborais ${ }^{(17)}$

A deformidade corporal é objeto de curiosidade humana, desde remotos séculos. Há relatos na literatura de uma série de atrocidades realizadas com seres humanos que possuíam algum tipo de deformidade. Estes eram atores nos chamados freak shows ou circo dos horrores. Ali homens, mulheres e até mesmo crianças eram apresentadas em meio a uma plateia curiosa, para exibição de sua "monstruosidade". O monstro homem torna-se objeto comercial e de lazer.

\section{O corpo e o autopreconceito}

O preconceito se manifesta por meio da discriminação à raça, à nacionalidade, à sexualidade, aos grupos religiosos, entre outros. O preconceito pode vir da própria pessoa, conhecido como autopreconceito, ou de terceiros. Os dois tipos estão relacionados com um conceito negativo preestabelecido a respeito de uma pessoa. $O$ autopreconceito parece ser o pior, pois remete continuamente, a autopunição, pelo fato de se acreditar ser inferior aos outros ${ }^{(18)}$.

Tâmares, 23 anos, casada, tentou suicídio meses jogando álcool no corpo. A reação do marido diante das cicatrizes foi normal, ela não está trabalhando e faz uso de malha compressiva em todas as partes queimadas do seu corpo. Logo após sua alta hospitalar, existiam algumas limitações funcionais, evitava sair de casa, pela dificuldade de locomoção e dores, porém, após participar dos cultos religiosos, passou a frequentar locais fora do ambiente doméstico:

"Eu deixei de sair por muito tempo, por que eu estava com dificuldade, depois comecei a ir à igreja o que me ajudou. Eu comecei a sair de casa para outros lugares, também."

Pessoas vítimas de queimaduras graves são constantemente silenciosas ao sofrimento físico e psíquico. Nos momentos iniciais após o trauma, o sofrimento físico está associado à dor da ferida, curativos e variadas cirurgias. $\mathrm{O}$ adoecimento psíquico ocasiona danos ainda maiores, podendo ser temporários ou permanentes ${ }^{(4)}$.

Relativamente à percepção corporal, ela acredita que nada vai mudar e sente intensamente o autopreconceito:

"Eu acho que o preconceito mesmo vem mais de mim, assim, dos outros eu nunca notei nada de diferente. Eu sempre imponho vários obstáculos, para mim acho que não vai melhorar nada."

$\mathrm{Na}$ aceitação da imagem corporal, há distintas maneiras de enfrentamento. Uns conseguem superar com facilidade, enquanto outros não aceitam as mudanças, pois não conseguem lidar com suas limitações. As interações com o mundo social e o equilíbrio interno que o ser humano deve manter dependerão da imagem corporal. No momento em que a pessoa não aceita seu corpo físico, tal fato pode introduzir um desequilíbrio emocional e desencadear distúrbios da autoimagem ${ }^{(19)}$.

A aparência normal é definida como um conceito individual derivado da percepção de igualdade de aparências alheias, conduzindo a uma percepção de normalidade. As opiniões pessoais não deixam de ser importantes, mas estão subordinadas a padrões estabelecidos pela coletividade ${ }^{(20)}$.

A relação conjugal de Tâmares em nada foi objeto de mudanças, o que modificou foi a sua percepção perante a nova imagem corporal:

"Sou casada e a reação do meu marido foi normal. Eu que não me via do mesmo jeito. Passei a me sentir feia. Acho que sou uma vergonha para a minha familia. Mas me apoio na minha fé para superar isso."

Vítimas de grandes queimaduras passam a expressar dificuldades na vida familiar e afetiva. Consolidam suas fragilidades preexistentes e demonstram dificuldades, encontradas pela própria vítima, o que interfere nas relações familiares. A influência da religiosidade/espiritualidade demonstra recorrentemente potencial, influência positiva, sobre a saúde física, causando um fator preventivo para superação de doenças ${ }^{(4,21)}$.

Lis, 19 anos, atentou contra a própria vida, após banhar-se com gasolina e riscar um fósforo. Relatou que, na fase inicial, sentia muito o preconceito vindo de si mesma, em razão das cicatrizes aparentes em sua face e membros superiores:

"No início eu tive preconceito comigo mesmo, só usava um lenço no meu pescoço e blusas de manga comprida. Eu ainda me sinto assim, mas busco em Deus para tirar tudo de ruim da minha mente." 
Maiores níveis de envolvimento religioso estão associados, positivamente, à satisfação com a vida, felicidade, moral elevado e menos pensamentos e comportamentos suicidas. Tudo isso efetiva a importância da religião como fator associado a uma melhor saúde mental ${ }^{(16)}$.

A religiosidade exerce a função de proteger, confortar e oferecer respostas às dificuldades da vida. A religião cria possibilidades de compartilhamento e interação com o outro, mediante seus rituais e orações. A atitude religiosa reorienta os marcadores identitários, possibilitando a pessoa habitar um local de comodidade e familiaridade do ponto de vista subjetivo ${ }^{(15)}$.

\section{CONSIDERAÇÕES FINAIS}

Pode-se notar a existência de vários fatores que influenciam no cotidiano das mulheres vítimas de queimaduras graves com cicatrizes hipertróficas. Essas vão além da limitação funcional e da percepção da autoimagem, pois envolvem complexos processos psicológicos, crenças, julgamento por parte da sociedade e redução da autoestima.

Percebeu-se que as práticas religiosas ajudam no enfrentamento de problemas complexos como doenças ou traumas que deixaram sequelas irreparáveis. Procurou-se proporcionar uma reflexão sobre a diversidade de facetas e a complexidade de situações que envolve a vida de mulheres que provocam a autodestruição da vida.

Espera-se, com essas reflexões, que as mulheres acometidas de queimaduras sejam melhores atendidas e compreendidas pelos profissionais de saúde e que esses considerem a importância da religião e da espiritualidade no empoderamento de pessoas que tentam contra a própria vida.

\section{REFERÊNCIAS}

1. Vale ECS. Primeiro atendimento em queimaduras: a abordagem do dermatologista. An Bras Dermatol. 2005;80(1): 9-19.

2. Santana CML, Brito DF, Costa ACSM. Fisioterapia na reabilitação do paciente queimado. Rev Bras Queimaduras. 2012;11(4):240-5.

3. Lovisi GM, Santos SA, Legay L, Abelha L, Valencia E. Análise epidemiológica do suicídio no Brasil entre 1980 e 2006. Rev Bras Psiquiatr. 2009;31(Supl 2):S86-S93.

4. Guimarães HP, Avezum Á. O impacto da espiritualidade na saúde física. Rev Psiquiatr Clín. 2007;34(Supl 1): 88-94.

5. Saad M, Masiero D, Battistella LR. Espiritualidade baseada em evidências. Acta Fisiátrica. 2001;8(3):107-12.

6. Civili TV, Finotti CS. Abordagem fisioterapêutica precoce em pacientes críticos queimados. Rev Bras Queimaduras. 2012;11(2):85-8.

7. Turato ER. Métodos qualitativos e quantitativos na área da saúde: definições, diferenças e seus objetos de pesquisa. Rev Saúde Pública. 2005;39(3):507-14.

8. Kleinman A. Patients and healers in the context of culture: an exploration of the borderland between anthropology, medicine, and psychiatry. Berkeley: University of California Press; 1980. v. 3.

9. Brasil. Conselho Nacional de Saúde. Resolução $n^{\circ}$ 466, de 12 de dezembro de 2012. Aprova normas regulamentadoras de pesquisas envolvendo seres humanos. Brasília: Diário Oficial da União, 2013.

10. Sanchis P. Desponta novo ator no campo religioso brasileiro? O Padre Cícero Romão Batista. Religião Sociedade. 2007;27(2):11-29.

11. Salgado MI, Freire G. Saúde e espiritualidade: uma nova visão da Medicina. Belo Horizonte: INEDE; 2008.

12. Faria MGA, David HMSL, Rocha PR. Inserção e prática religiosa entre mulheres: aspectos protetores ao uso de álcool e violência. SMAD Rev Eletrônica Saúde Mental Álcool Drog. 2011;7(1):32-7.

13. Santos ARM, Dabbicco P, Cartaxo HGO, Silva EAPC, Souza MRM, Freitas CMSM. Revisão sistemática acerca da influência da religiosidade na adoção de estilo de vida ativo. Rev Bras Promoç Saúde. 2013;26(3):419-25.

14. McCullough ME, Willoughby LB. Religion, self-regulation, and selfcontrol: associations, explanations, and implications. Psychol Bull. 2009;135(1):69-93. 
15. Figueiredo AEB, Silva RM, Vieira LJES, Mangas RMN, Sousa GS, Freitas JS, et al. É possível superar ideações e tentativas de suicídio? Um estudo sobre idosos. Ciênc Saúde Colet. 2015;20(6):1711-9.

16. Faria JB, Seidl EMF. Religiosidade e enfrentamento em contexto de saúde e doença: uma revisão de literatura. Psicol Reflex Crit. 2005;18(3):381-9.

17. Baialardi KS. O estigma da hanseníase: relato de uma experiência em grupo com pessoas portadoras. Hansen Int. 2007;32(1):27-36.

18. Courtine JJ. O corpo anormal: história e antropologia culturais da deformidade. In: Corbin A, Courtine JJ, Vigarello G, organizadores. A história do corpo: as mutações do olhar no século XX. Petropólis: Vozes; 2008. p. 253-340.

19. Palmeira IP, Queiroz ABA, Ferreira MA. Marcas em si: vivenciando a dor do (auto) preconceito. Rev Bras Enferm. 2013;66(6):893-900.

20. Botelho FM. Corporalidade e estigma: estudo qualitativo com pacientes em reabilitação de queimaduras [dissertação]. Ribeirão Preto: Universidade de Ribeirão Preto/USP; 2012

21. Benute GRG, Bordini DCN, Juhas TR, Cabar FR, Pereira PP, Lucia MCS, et al. Depression, stress and guilt are linked to the risk of suicide associated to ectopic pregnancy. MedicalExpress (São Paulo). 2016;3(3):1-5.

\section{Endereço para correspondência:}

Rafaele Teixeira Borges

Faculdade Ateneu - FATE

Rua Manoel Arruda, 70

Bairro: Messejana

CEP: 60.863-315 - Fortaleza - CE - Brasil

E-mail: rafaele_borges@hotmail.com 